\title{
APONTAMENTOS SOBRE A EDUCAÇÃO DE IMIGRANTES NO BRASIL
}

\author{
Área Temática: Ciências Humanas/História \\ Amanda Dutra Hot ${ }^{1}$ \\ ${ }^{1}$ Mestre em História pela UFOP e professora da Faculdade de Ciências Gerenciais de \\ Manhuaçu (FACIG).
}

\section{RESUMO}

A educação de imigrantes no Brasil, especificamente no final do século XIX e início do século XX, passou por um processo de transformação ligado à política brasileira e à conjuntura da situação internacional.

Se num primeiro momento, a chegada dos imigrantes fez surgirem escolas situadas em suas vilas, onde a educação priorizava a manutenção de suas tradições européias; podemos observar, posteriormente, uma reconfiguração dessa atividade frente às transformações que as épocas exigiam.

Neste sentido, buscaremos apresentar como se iniciou o processo de educação de imigrantes no Brasil, através das medidas governamentais e de ações oriundas a partir das próprias comunidades estrangeiras. Torna-se interessante ressaltarmos as deficiências e as dificuldades inerentes a essa ação historicamente construída a partir do Brasil monárquico.

Palavras-chaves: Educação; Imigrantes; Política

\section{ABSTRACT}

The education of immigrants in Brazil, specifically in the late nineteenth and early twentieth century, has undergone a transformation process on the Brazilian political situation and the international situation.

If at first, the arrival of immigrants gave rise to schools in their villages, where education prioritized maintaining its European traditions, we can see later, a reconfiguration of this activity face the transformations that the times demanded.

In this sense, try to present as began the process of educating immigrants in Brazil, through government measures and actions arising from the foreign communities themselves. It is interesting to emphasize the shortcomings and the difficulties inherent in this action historically constructed from Brazil monarchy.

Keywords: Education; Immigrants; Policy 


\section{CHEGADA DE IMIGRANTES NO BRASIL NOS SÉCULOS XIX E XX}

Com a proclamação da independência, em 1822, surge uma preocupação no interior do Estado brasileiro: se fazia urgente um planejamento de Estado, uma construção do sentimento de nação e da memória nacional.

O processo pelo qual haviam passado os EUA, muitas vezes associado à grandes levas de imigrantes que lá chegaram, começou a ser visto como um exemplo a ser seguido por outros países.

Esse processo talvez tenha sido o marco para o início das políticas incentivadoras à imigração no Brasil. Outros fatores também contribuíram para essa demanda de imigrantes, tais como a rápida expansão do povoamento que se daria a partir dos mesmos; o incentivo à pequena propriedade; a urbanização e crescimento das cidades; o incremento das atividades manufatureiras; a garantia de ocupação do espaço geográfico e, portanto, a diminuição de querelas de fronteiras no sul do Brasil; e, por fim, o que muitos historiadores denominaram de "branqueamento" do país (LOPES, 2003, p. 349).

A política de imigração elaborada pelo governo brasileiro teve início em meados do século XIX, incentivando a vinda desses imigrantes e "financiando" todo ou boa parte do seu processo de chegada. Ao chegarem, alemães, italianos, japoneses, poloneses, eram instalados em propriedades privadas de fazendeiros, cafeicultoras em sua maioria. A partir de então o imigrante "teria" um pedaço de terra, onde trabalharia para si, além de trabalhar na fazenda do proprietário das terras. Mas, por hora, não é esse aspecto econômico que nos importa, mas o relativo às formas desenvolvidas por esses europeus para manterem grupos homogêneos e coesos, favorecendo a manutenção de sua cultura.

A política brasileira priorizou, desde sempre, a imigração européia (branca), favorecendo, assim, a formação de colônias etnicamente homogêneas. Essas colônias foram fortemente marcadas por iniciativas visando à manutenção de sua cultura, como o idioma, a religião e a organização escolar.
Estas duas últimas, unidas, foram tão aplicadas que persistem nos dias atuais, como veremos em próximos tópicos.

\section{AS ESCOLAS ÉTNICAS E SEUS EXEMPLOS}

O que podemos identificar com o processo educacional entre imigrantes no Brasil era bastante diferenciado entre seus diversos grupos. Um levantamento da Secretaria da Agricultura de São Paulo, feita entre 1908 e 1932, registrou o índice de alfabetização dos imigrantes que entraram pelo porto de Santos. Onde o grau de alfabetização por grupo étnico foi o seguinte:

.Imigrantes alemães: $91,1 \%$ .Imigrantes Japoneses: 89,9\% .Imigrantes italianos: $71,3 \%$ .Imigrantes portugueses: $51,7 \%$ .Imigrantes espanhóis: $46,3 \%$

Mas esses dados referem-se somente aos imigrantes que entraram pelo porto de Santos e não podem ser tomados como representação completa de cada grupo étnico. Estudos indicam que mesmo entre os grupos, com maior tradição escolar havia variações consideráveis dependendo da região de proveniência. No período de maior entrada dos mesmos, na década de 1890 , - Brasil tinha um sistema escolar altamente deficitário, com uma população de mais de $80 \%$ de analfabetos (GOMES, 2000). Esse quadro levou alguns grupos de imigrantes a pressionarem o Estado em favor de escolas púbicas. Outros, especialmente os que haviam se estabelecido em núcleos mais homogêneos, investiam em escolas étnicas.

As escolas de imigrantes não tinha uma forma padrão, dependiam de cada região onde elas se encontravam, se estavam em zona rural ou em centros urbanos e também no Estado que se encontravam. As escolas dos imigrantes 
podiam ser comunitárias, particulares e/ou pertencentes a uma congregação religiosa.

A etnia com maior número de escolas de imigração no Brasil até 1939 foi a dos imigrantes alemães, com 1.579 escolas, seguindo-se a dos imigrantes italianos, com 396 escolas em 1913 (e 167 escolas na década de $30)$. Os imigrantes poloneses tiveram 349 escolas e os imigrantes japoneses 178 (GOMES, 2000).

Entre outros grupos de imigrantes também houve algumas iniciativas de escolas étnicas, porém em pequeno número. Vejamos agora como funcionavam duas das principais escolas de imigrantes:

\section{ESCOLAS DE IMIGRAÇÃO ALEMÃ}

Os imigrantes alemães vieram de regiões com acentuada tradição escolar. Não encontrando escolas públicas na região de imigração, uniram-se para construção de escolas étnicas, manutenção do professor e produção de material didático. A estrutura física dos núcleos rurais favorecia a união de 80 ou mais famílias em torno de uma estrutura comunitária básica, na qual a escola vinha em primeira instância. Nos primeiros anos usavam cartilhas manuscritas e em 1832, oito anos após a chegada dos pioneiros, imprimiram 0 primeiro abecedário para suas escolas.

Até 1875 o crescimento foi lento, havia no Rio Grande do Sul 99 escolas da imigração alemã, sendo 50 católicas e 49 evangélicas. Porém, a partir de então, o processo escolar começou a ser assumido mais diretamente pelas igrejas, respectivamente católica e evangélica, recebendo conotação confessional. $\mathrm{Na}$ passagem do século eram 308 escolas da imigração alemã no RS.

A partir de 1900, o processo escolar dos imigrantes, predominantemente no Rio Grande do Sul e Santa Catarina, teve um grande surto de desenvolvimento. Além de ampla produção de material didático, foi criada toda uma estrutura de apoio para o processo escolar. Em nível confessional, católicos e luteranos tiveram sua associação de professores, seu jornal do professor, sua escola normal, suas reuniões locais e regionais de professores, cursos e semanas de estudo e amplo incentivo à produção de material didático. Em nível interconfessional e interestadual, professores teuto-brasileiros tiveram um fundo de pensão e aposentadoria, realizaram congressos e criaram a Associação Brasileira de Professores da Imigração Alemã.

Em 1937, segundo o levantamento das Associações de professores (HACK, 1967), o número de escolas da imigração alemã no Brasil era 1.579, distribuindo-se da seguinte maneira pelos estados:

$$
\begin{aligned}
& \text { Rio Grande do Sul - } 1.041 \text {. } \\
& \text { Santa Catarina - } 361 \text {. } \\
& \text { São Paulo }-61 . \\
& \text { Rio de Janeiro }-16 . \\
& \text { Espírito Santo - } 67 \text {. } \\
& \text { Outros Estados }-33 \text {. }
\end{aligned}
$$

As escolas de imigração alemã na região rural eram escolas comunitárias porque foram criadas e mantidas pelas comunidades teuto-brasileiras. Porém, na maior parte dos casos, eram consideradas também escolas confessionais. As estruturas de apoio eram animadas e supervisionadas pelas respectivas confissões religiosas. As igrejas, católica e evangélica, assumiam a questão escolar como seu principal ponto de apoio para a ação continuada e estruturada nos núcleos rurais.

$\mathrm{E}$, em contrapartida, para quem não se comprometesse com a escolarização dos filhos e a manutenção da escola e do professor, as sanções também eram religiosas. Esse projeto não seria aceito, não valeria de forma idêntica, no essencial, para mais de mil núcleos rurais se não houvesse um forte simbolismo, com ampla rede de associações criadas e dinamizadas numa perspectiva comum.

Isto permitiu que nas décadas de 20 e 30 , quando 0 índice nacional de analfabetismo ainda estava em torno de $80 \%$, os núcleos de imigrantes alemães tivessem poucos analfabetos. 


\section{ESCOLA DA IMIGRAÇÃO ITALIANA}

Também podemos falar genericamente de escolas da imigração italiana. Há diferenciações motivadas pela região de proveniência dos imigrantes, pelo contexto socioeconômico regional no qual se inseriam (região urbana, trabalhador assalariado em fazenda de café ou pequeno proprietário de terra em localidades etnicamente homogêneas) e também pelas diferenciadas iniciativas dos estados em relação ao processo escolar, uma vez que na Primeira República o ensino primário era responsabilidade dos mesmos. $O$ Ministério de Relações Exteriores do governo italiano, que dava subsídio a essas escolas, especialmente por meio de material didático.

Dependendo da região de proveniência, os imigrantes italianos tinham maior ou menor vinculação com o processo escolar.

Senso no Porto de Santos registra que $71,36 \%$ dos imigrantes italianos que entraram por este porto eram alfabetizados. Já o senso do porto de Alfredo Chaves (RS) de 1906 mostra um alto grau de analfabetos (HACK, 1967). Dos 22.707 habitantes, 16.110 eram analfabetos. A igreja era o centro para a organização cultural. Não estabeleciam vinculação direta entre igreja e escola. Interessavam-se relativamente pouco pela construção de escolas, atribuíam esta tarefa ao poder público e às congregações religiosas.

\section{O GOVERNO BRASILEIRO E AS POLÍTICAS EM RELAÇÃO À EDUCAÇÃO DE IMIGRANTES}

Como já sabemos, o período em que houve um grande contingente de imigrantes para o Brasil, foi no final do século XIX e início do século $X X$. Neste mesmo momento, o país buscava delinear a construção de uma identidade nacional. Este conceito de identidade, como define Lúcia Lippi Oliveira "(...) é um processo de construção, na qual a identidade tem uma dimensão interna em que se acentuam os traços de similaridade $e$, ao mesmo tempo, uma dimensão externa, que define uma diferença em relação ao outro" (OLIVEIRA, 1990, p. 11). O conceito de nação tem seu início no século XVIII, com a emergência na luta política e social dos povos europeus e que marcaram igualmente a história do Novo Mundo. A idéia de nação visa proporcionar sentimentos de identidade a uma população que vive ou que se originou em um mesmo território. A consciência nacional está intimamente interligada com - processo de construção do Estadonacional (OLIVEIRA, 1990, p. 11). Entretanto nem sempre a consciência precede a nação, qual fator vem antes ou depois depende de outros aspectos, como a própria formação do Estado. No caso dos Estados europeus o problema foi o de construir um Estado Nação no interior da nacionalidade, no caso da América Portuguesa e Espanhola seria construir uma nacionalidade dentro do Estado Nação.

Neste sentido, verificamos que a imigração ocorreu no momento histórico internacional de ênfase na formação da nacionalidade. $\mathrm{O}$ nacionalismo desencadeava um movimento de afirmação de uma unidade simbólica, necessária pela modernização econômica. Desta forma, veremos como a questão da educação se inseria neste espaço dos objetivos que estavam sendo alcançados pela nação brasileira.

De acordo com Lúcio Kreutz,

\begin{abstract}
A educação brasileira apoiava-se na expansão de um sistema escolar igualitário, com a função de difundir uma cultura uniforme. Inventara culturas amplamente desprovidas de toda base étinica, com a finalidade de unificar $O$ imaginário das nações. KREUTZ, 2003, p. 351)
\end{abstract}

A escola foi chamada a ter um papel central na configuração de uma identidade nacional, sendo ao mesmo tempo um elemento de incentivo à exclusão de processos identitários étnicos. Ou seja, a escola deveria se 
ativada em perspectiva monocultural, tratando as diferenciações culturais como algo a ser superado.Desta forma, como as escolas étnicas conseguiram se enquadrar no sistema que o governo brasileiro delineava?

As iniciativas dos imigrantes em relação ao processo escolar devem ser entendidas nessa perspectiva, isto é, vinculadas ao momento histórico da nacionalidade, cuja afirmação, rearticulação se dá em relação ao privilegiamento ou à negação de processos identitários étinicos. Logo, houve uma história de lutas pela determinação de suas metas e valores para que cada grupo étnico conseguisse criar um processo educacional capaz de realizar a formação dos alunos.

Entretanto, a partir de 1930, numa tendência política crescentemente nacionalista, as escolas étnicas já começaram a sofre com certas restrições governamentais. O governo, em nível federal e estadual, após ter encorajado e depois tolerado a iniciativa dos imigrantes em relação ao processo escolar, realçando que mantinham com esforço próprio o que na verdade era dever do Estado, começou a interferir nas escolas étnicas. No período de 1938-1939, muitas destas escolas foram fechadas ou transformadas em escolas públicas por meio de uma seqüência de decretos de nacionalização. Apesar de alguns estados, como o Rio Grande do Sul que foi mais tolerante com as escolas de língua estrangeira, o governo brasileiro coibiu o uso de idiomas que não o português e fechou temporariamente a imprensa de grupos étnicos. Exatamente no final da década de 30 é que veríamos o final das escolas dos imigrantes, já que havia medidas que barravam o progresso deste tipo de educação. Em 1938, teve um decreto que ordenou que todo o material usado na escola elementar fosse em português, que todos os professores e diretores de escola fossem brasileiros natos, que nenhum livro de texto, revista ou jornal circulasse em língua estrangeira nos distritos rurais e que o currículo escolar tivesse instrução adequada em história e geografia do Brasil.

Por fim, é interessante perceber que não foram somente as medidas restritivas do governo que levaram ao término das escolas étnicas. Como corrobora Lúcio Krutz neste período já estavam em curso umas séries de fatores que aos poucos provocaram a transformação do projeto escolar dos imigrantes. De acordo como o autor: "a estrutura escolar e comunitária começava a ceder a pressões internas e externas" (KREUTZ, 2003, p. 367). Internamente havia uma tendência crescente de pais e alunos que sentindo a necessidade de se habilitarem melhor no aprendizado do português e de terem melhores condições para os desafios da atividade profissional aderiram ao apelo da escola pública gratuita. $O$ aspecto externo está relacionado com a quebra do isolamento anterior dos núcleos rurais que abriram caminho para as transformações socioeconômicas. Desta forma, as medidas de nacionalização compulsória do ensino apenas precipitaram em processo de transformação já em curso.

\section{ESCOLA AMERICANA: UMA NOVA PERSPECTIVA DO ENSINO ESTRANGEIRO NO BRASIL}

De acordo com o que estamos apresentando, o processo de educação de imigrantes sempre se mostrava dificultoso durante os primeiros tempos do nosso império.

O monopólio religioso católico definido para o Estado brasileiro a partir da Constituição de 1824 fazia com que, em nosso país, se passasse um processo histórico diferente daquele que ocorria na Europa ou nos Estados Unidos, já movimentados pela Revolução Francesa ou pelo ecos da Revolução norteamericana. Dentre os diversos constrangimentos pelos quais passavam os estrangeiros protestantes que chegavam ao Brasil oficialmente católico, podemos observar: "Todos os que podem eleitores são hábeis para serem nomeados deputados. Excetuam-se $\{\ldots\}$ 
III- Os que não professarem a religião do Estado. $^{3}$

Diante das escolas do império, as famílias de imigrantes protestantes viam dificultados seu ingresso e permanência, além do que a conhecida inadequação e a grande defasagem desse ensino não condiziam com as transformações em curso no campo das ciências ao longo do século XIX. Frente a toda esta situação, uma solução encontrada pelos estrangeiros foi a busca da implantação das suas escolas particulares que, além de ensinarem os princípios religiosos protestantes, cuidavam ainda de aulas de inglês e também alemão; tudo sob a vigilância - ora presente, ora distante - dos órgãos imperiais. E estes temiam especialmente pelo espalhamento e cultos e práticas que ferissem suas determinações políticas ou as religiosas da Igreja Católica.

Ao longo dos dois reinados no Brasil os imigrantes vão conquistando cada vez maior espaço e liberdade para exercer seu culto juntamente com a educação de seus filhos, uma vez que: "para eles era uma questão vital o cuidado da família e a orientação religiosa e vocacional" (HACK, 2003, p. 14). E ainda consistia como principal interesse dos recémchegados ao Brasil:

depois de Ter providenciado alimento e abrigo, foram trabalhar para 0 estabelecimento do culto religioso e de escolas para seus filhos $\{\ldots\}$ à necessidade de instituições religiosas juntava-se ao de ter escolas apropriadas para seus filhos. (JONES, 1967, p. 123)

Escolas protestantes começaram a surgir no Brasil a partir de 1820, através das chamadas escolas comunitárias. Estas tinham 0 objetivo de atender prioritariamente às famílias de imigrantes, com professores e pastores vindos de seus países de origem para atender às necessidades dessas comunidades. Através dessas escolas - concentradas nas vilas e

\footnotetext{
${ }^{3}$ Dizeres presentes na Constituição Brasileira de 1824. Art. 95. Inc.III.
}

povoações de imigrantes - o ensino consistia basicamente em formas de se preservar seus costumes, língua, tradições e princípios religiosos.

Vale destacar que uma nova guinada no que diz respeito à educação de imigrantes protestantes, é dada a partir da Segunda metade do século XIX. Na década de 1870, com o incremento das missões presbiterianas norte-americanas, teriam início as chamadas Mission Schools, entidades que teriam a finalidade de atender não apenas aos filhos de imigrantes, protestantes ingleses e norteamericanos - que consistiam nos maiores contingentes - mas também a um público brasileiro que por razões quer politicoreligiosas, quer morais e intelectuais, não conseguiam se adequar aos traços romanizadores da educação brasileira.

No decorrer da Segunda metade do oitocentos, seriam espalhadas Brasil afora mais de quarenta instituições particulares de ensino protestante; que se desenvolviam a partir das grandes lacunas deixadas pela educação imperial, como podemos perceber em uma lei estabelecida para o governo de São Paulo em 1869:

$$
\begin{aligned}
& \text { seu artigo } 8^{\circ} \text { autorizava a } \\
& \text { supressão de escolas públicas } \\
& \text { elementares que não atingissem a } \\
& \text { freqüência mínima de } 20 \text { alunos. } \\
& \text { Também suprimia uma delas na } \\
& \text { mesma cidade quando a soma dos } \\
& \text { alunos não atingia } 50 .
\end{aligned}
$$

Podemos perceber que as lacunas geradas pela ação governamental brasileira em relação à educação que se dispunha para sua população, os colégios de estrangeiro passaram a concorrer com a educação governamental. Nesse contexto, vale destacar a criação, em 1870, de um Colégio Americano em São Paulo, levado adiante pelo missionário George Chamberlain, que percebia a educação - acompanhada da religião - 
como um processo transformador da sociedade.

Esta instituição de ensino tornava o hoje conhecido Mackenzie College a partir de 1898, uma instituição educacional onde buscava-se sempre associar a educação teórica com a prática; sendo os alunos preparados para o trabalho e para a vida. Este sistema educacional em função dos colégios protestantes ganhará cada vez mais destaque a partir da proclamação da república brasileira, que culmina com a eliminação da prioridade política da Igreja Católica.

Portanto, podemos pensar que as escolas presbiterianas, que começaram destinadas apenas aos filhos de imigrantes na sua comunidade local, se reconfiguraria em um centro de estudos também para brasileiros republicanos, abolicionistas e liberais, todos desgostosos dos rumos dados pelo império aos destinos da nação e da educação que se conferia à população.

Com a evolução do Mackenzie College ganham destaque no Brasil os cursos ginasiais - que não eram priorizados pelo Estado - e também os cursos superiores - uma completa raridade no Brasil da época - nas áreas de Teologia, Filosofia e Normal Superior e também Engenharia e Comércio. Estes dois últimos ganham muito destaque nos inícios do século $\mathrm{XX}$, onde especialmente o curso comercial, segundo Antônio M. Gomes (GOMES, 2000), teria participação decisiva na formação do empresariado paulista desse período; além de grandes nomes da política nacional, como Rui Barbosa e Prudente de Morais.

\section{CONCLUSÃO}

Dado o exposto, percebemos que as escolas étnicas foram uma forma que os imigrantes, que aqui chegaram, encontraram para manter grupos mais ou menos coesos, bem como sua tradição cultural.

Verifica-se que no sul do Brasil, por exemplo, essas escolas étnicas tiveram uma maior liberdade de ação, devido à concentração dos mesmos nessa região, especialmente alemães e poloneses. Em resultado disso uma maior autonomia nos assuntos ligados à educação se fez presente, embora as dificuldades e as conquistas caminhassem juntas ao longo do tempo.

A partir da década de 1930, o governo brasileiro se torna mais rigoroso e normatizador com as legislações coibitivas ligadas à educação de imigrantes. Como medidas do governo nacionalista proposto por Vargas, veríamos o fim da distribuição de livros didáticos em língua estrangeira, todos os professores e diretores de escolas públicas deveriam ser brasileiros natos $e$ proibiam o ensino de língua estrangeira a menores de 14 anos. No âmbito privado, as entidades estrangeiras - vide 0 Colégio Mackenzie - vão conservar uma maior liberdade de organização.

\section{REFERÊNCIAS BIBLIOGRÁFICAS}

GOMES, Antônio Máspolí de Araújo. Religião, educação e progresso. São Paulo: Editora Mackenzie, 2000.

HACK, Osvaldo Henrique. Raízes cristãs do Mackenzie e seu perfil confessional. São Paulo: Editora Mackenzie, 2003.

JONES, Judith M. Soldado descansa: uma epopéia norte-americana sob os céus do Brasil. São Paulo: Jarde, 1967.

KREUTZ, Lúcio. A educação de imigrantes no Brasil. In: LOPES, Eliane Marta Teixeira; FARIA FILHO, Luciano Mendes \& VEIGA, Cynthia Greive. $\mathbf{5 0 0}$ anos de educação no Brasil. $3^{a}$.ed. Belo Horizonte: Autêntica, 2003.

OLIVEIRA, Lúcia Lippi. A Questão Nacional na Primeira República. São Paulo: Brasiliense, 1990. 